Article

\title{
Synthesis, Characterization and Properties of Antibacterial Polyurethanes ${ }^{\dagger}$
}

\author{
Jihua Duan ${ }^{1}$ and Guichang Jiang ${ }^{1,2, *}$ \\ 1 College of Light Industry Science and Engineering, Tianjin University of Science and Technology, \\ Tianjin 300222, China; djh@163.com \\ 2 Department of Chemistry, Tsinghua University, Beijing 100084, China \\ * Correspondence: gcj@tust.edu.cn; Tel./Fax: +86-2260-274-489 \\ † Extended Conference Paper of 2016 Global Conference on Polymer and Composite Materials, \\ Hangzhou, China, 20-23 May 2016.
}

Citation: Duan, J.; Jiang, G. Synthesis, Characterization and Properties of Antibacterial Polyurethanes. Polymers 2022, 14, 213. https://doi.org/ $10.3390 /$ polym 14010213

Academic Editor: Xing Wang

Received: 9 November 2021

Accepted: 29 December 2021

Published: 5 January 2022

Publisher's Note: MDPI stays neutral with regard to jurisdictional claims in published maps and institutional affiliations.

Copyright: (C) 2022 by the authors. Licensee MDPI, Basel, Switzerland. This article is an open access article distributed under the terms and conditions of the Creative Commons Attribution (CC BY) license (https:// creativecommons.org/licenses/by/ $4.0 /)$.

\begin{abstract}
Novel physically crosslinked polyurethane (PUII), based on isophorone diisocyanates, was prepared by a conventional two-step method. The chemical structures of the PUII were characterized by fourier transform infrared (FTIR), proton nuclear magnetic resonance $\left({ }^{1} \mathrm{H} N M R\right)$, gel permeation chromatography (GPC), scanning electron microscopy (SEM) and DSC. The PUII hydrogels were subjected to solvent-induced self-assembly in THF + water to construct a variety of morphologies. The self-assembly morphology of the PUII was observed by scanning electron microscopy (SEM). The PUII films with different amounts $(0.2 \%, 0.4 \%, 0.6 \%, 0.8 \%, 1.0 \%)$ of 1,3,5-Tris(2-hydroxyethyl)hexahydro1,3,5-triazine (TNO) were challenged with Escherichia coli, Staphylococcus aureus, Bacillus subtilis and Gray mold. The results showed that when a small amount of antibacterial agent were added, the antibacterial effect of films on Botrytis cinerea was more obvious. The mechanical evaluation shows that the antimicrobial polyurethane films exhibit good mechanical properties.
\end{abstract}

Keywords: polyurethanes; morphology; electron microscopy; self-assembly

\section{Introduction}

Polyurethanes (PUs) are one of the crucial classes of polymers with wide applications and properties, because their properties can easily be tailored by varying the components from which they are constructed [1-7]. Polyurethanes offer excellent versatility in terms of their mechanical properties and are widely applied in many fields [8-19]. In general, the synthesis of polyurethanes is carried out in two stages. The first stage is the synthesis of a prepolymer containing free isocyanate groups and in the second stage there are reactions of chain extension or crosslinking of the polymer chains. PUs are composed of hard segments and soft segments. In the hard segments, the polar groups of urethane form hydrogen bonds. The hard domains act as physically cross-linked sites and thus reinforce the PUs' structure. However, the morphology and mechanical properties depend heavily on the kinds of soft segments [2]. Self-assembled polyurethanes (PUs) are a special class of biodegradable and biocompatible materials that are currently used in tissue engineering and drug delivery applications [18]. Polyurethanes exhibit many desirable characteristics for their diverse applications in coatings, adhesives, sealants, elastomers and plastics [20].

Traditionally, PUs are compounds of diisocyanate monomers such as 4,4-diphenylmethane diisocyanate (MDI) and polyatomic alcohol such as PTMG [21,22]. The polyurethanes obtained with these diisocyanates are easily oxidized and this causes the color change of the products. Under ultraviolet light, a urethane bond is easily damaged and ethyleniminoquinone is generated, so we always find that the color of PUs made by MDI turns yellow [23]. Compare with MDI, isophorone diisocyanates (IPDI) has excellent light stability and chemical resistance [24]. It is generally used in the manufacture of high-grade 
polyurethane resin. Traditionally, PUs are industrially produced by reacting petroleumbased polyols with isocyanates. The traditional synthesized polyurethane has high elasticity and strong bonding characteristics [25]. It can be used for the production of polyurethane adhesives. This kind of adhesive can be used for bonding metal, plastic, paper, wood and other materials. In the packaging field, the polyurethane adhesives are mainly used for bonding two or more layers of plastic film, especially dry composite film. The composite plastic film was mainly used in packaging pharmaceuticals, food and other goods. In addition, the polyurethane adhesives can also be used for the composition of paper and plastic [26]. In the biomedical packaging area, polyurethane has been used to develop polyurethane adhesives; however, no publication indicates its use in packaging products with polyurethane [27]. Hence, it is very important to investigate the possibility of the application of antimicrobial polyurethane film to package biomedical product. However, pure polyurethane has little antibacterial activity and it is easy to breed bacteria when the external environment is suitable. It is necessary to improve the antibacterial activity of polyurethane by incorporating antibacterial agents. Abbas Mohammadi [28] introduced Silver into a Schiff base ligand extended polyurethane to obtain a highly stable antibacterial dispersion. Kai Liu [29] modified polyurethane with lysozyme. Shazia Muzaffar [30] modified polyurethane with low molecular weight chitosan. In addition, TNO is also a good antibacterial agent. In this work, TNO was incorporated into polyurethane. In a previous publication, we used a macroiniferter-controlled radical polymerization method to successfully synthesize novel fluorinated polyurethanes and showed their interesting biological and mechanical properties that merit potential applications as biomaterials for tissue engineering [31].

Copolymer self-assembly behavior has been a hot research topic in recent years. By the structure or properties of different chain segments through chemical bond connected and block copolymers, microphase separation phenomenon will happen under certain conditions, and the formation of the various dimensions of nanometer or submicron structure will form. Self-assembly process and the formation of structure can be controlled by the chain segment of the chemical structure [32-34], chain length, the regulation of the connecting way $[35,36]$ and the category and function of the external force field $[37,38]$. Self-assembly in the classic sense can be defined as the spontaneous and reversible organization of molecular units into ordered structures by non-covalent interactions. Self-assembled polyurethanes (PUs) are currently used in tissue engineering and drug delivery applications [18].

In this study, a novel physically crosslinked polyurethane (PUII) was synthesized by utilizing isophorone diisocyanates. In order to suppress interference of other substance, we synthesize PUII without dissolvent. The final products are characterized by FTIR, ${ }^{1} \mathrm{H}$ NMR, GPC and SEM. Finally, the assembly behavior of PUII was investigated by SEM. The biocidal activity was examined by using the inhibition zone method.

\section{Experimental Methods}

\subsection{Materials}

IPDI (Aladdin, Shanghai, China) was used without further purification. Polytetramethylene oxide (PTMG, Mw = 2000) (Aladdin, Shanghai, China) was dried at $90{ }^{\circ} \mathrm{C}$ in vacuum for 48 h. 1,4-Dihydroxybutane (BDO) (Aladdin, Shanghai, China) and tetrahydrofuran (THF) (Aladdin, Shanghai, China) were used as received. 1,3,5-Tris(2-hydroxyethyl)hexahydro1,3,5-triazine (TNO) (Aladdin, Shanghai, China) was dewatered before use. All other reagents (Aladdin, Shanghai, China) and solvents (Aladdin, Shanghai, China) were used as received without further purification.

\subsection{Preparation of PUII}

PUII was prepared by two-step addition polymerization. A $250 \mathrm{~mL}$ glass reactor equipped with a heating element, a mechanical stirrer, a charging and sampling port, and a nitrogen inlet and outlet was charged with polytetramethylene oxide $2000(15 \mathrm{~g}, 0.0075 \mathrm{~mol})$ and isophorone diisocyanates $(4 \mathrm{~g}, 0.018 \mathrm{~mol})$ in a 1:2.4 mol ratio. The mixture was heated to $60-70{ }^{\circ} \mathrm{C}$ and allowed to react for $3 \mathrm{~h}$. After $3 \mathrm{~h}$, a small amount of BDO as chain 
extender was added and allowed to react for $60 \mathrm{~min}$. Samples were frequently taken for FTIR analyses and reaction was allowed to proceed until the peak relating to the isocyanate $\left(2265 \mathrm{~cm}^{-1}\right)$ disappeared from the FTIR spectrum. The PUII was precipitated by pouring it into a water-methanol mixture $(1: 3 \mathrm{v} / \mathrm{v})$ and dried at $30^{\circ} \mathrm{C}$ in a vacuum oven (Scheme 1). Molecular weight: $7.9 \times 10^{4} \mathrm{~g} / \mathrm{mol}(\mathrm{Mn})$. IR (Figure 1a): $3328 \mathrm{~cm}^{-1}(-\mathrm{NH}), 2939 \mathrm{~cm}^{-1}$ $(-\mathrm{CH}), 1707 \mathrm{~cm}^{-1}(\mathrm{C}=\mathrm{O}), 1546 \mathrm{~cm}^{-1}(-\mathrm{CN}), 1239 \mathrm{~cm}^{-1}$ (C-O-C, PUII), $1108 \mathrm{~cm}^{-1}$ (C-O-C, PTMG). ${ }^{1} \mathrm{H}$ NMR (The spectrum was taken in $\mathrm{CDCl}_{3}$, Figure 2): $\delta=0.96-0.98 \mathrm{ppm}(\mathrm{d}, \mathrm{e}$, f, $\mathrm{CH}_{3}$, IPDI), $1.62-1.63 \mathrm{ppm}$ (b, $\left.\mathrm{CH}_{2}, \mathrm{PTMG}\right), 3.06 \mathrm{ppm}$ (g, $\left.\mathrm{CH}_{2}, \mathrm{IPDI}\right), 3.40-3.41 \mathrm{ppm}$ (c, $\left.\mathrm{CH}_{2} \mathrm{O}, \mathrm{PTMG}\right), 4.06-4.07$ ppm (a, $\left.\mathrm{OCH}_{2}, \mathrm{PTMG}\right), 7.29$ ppm (h, NH, PUII).
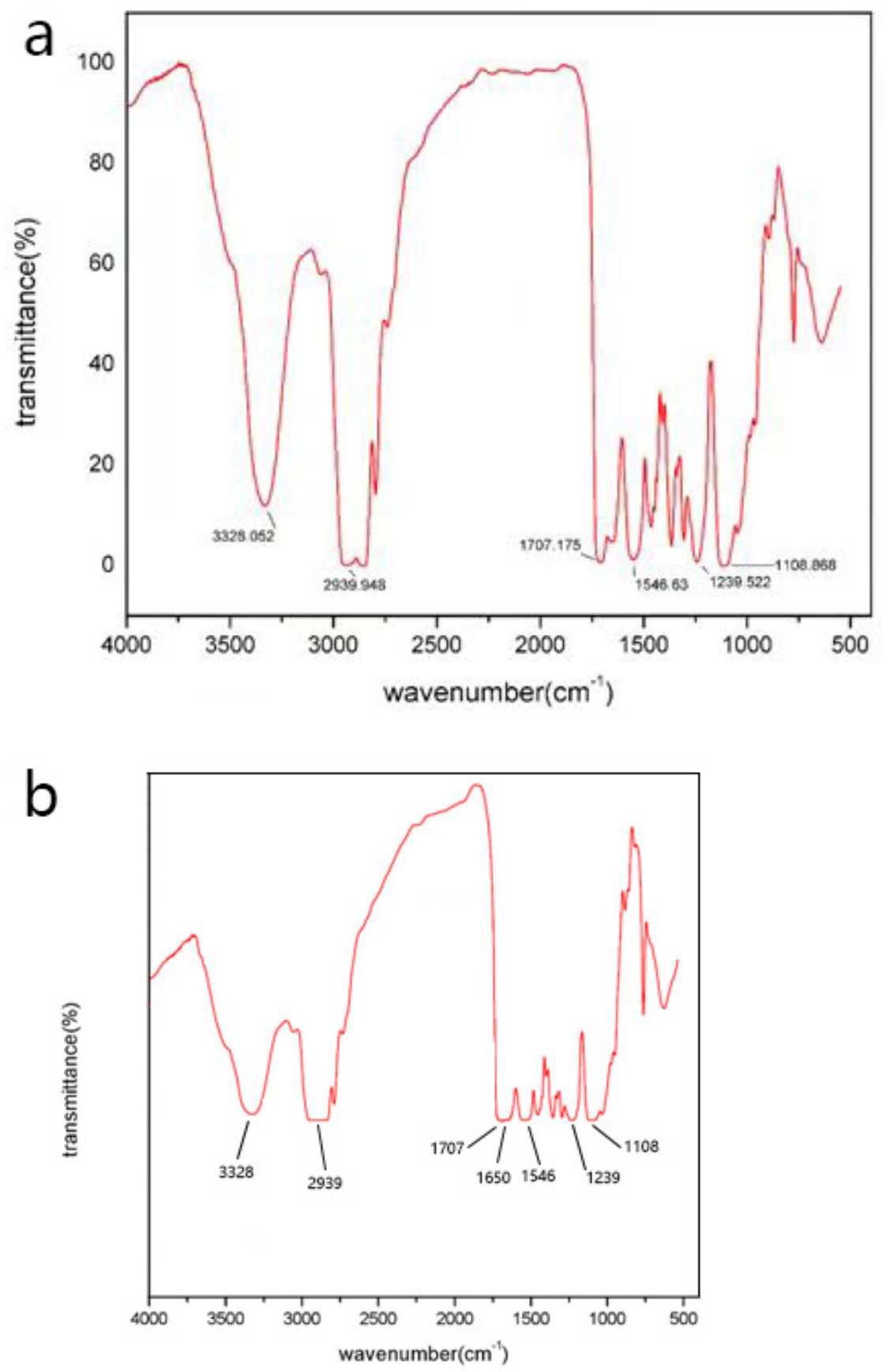

Figure 1. FTIR spectrum of polyurethane (PUII) (a), and polyurethane (PUII) with antibacterial agent (b). 


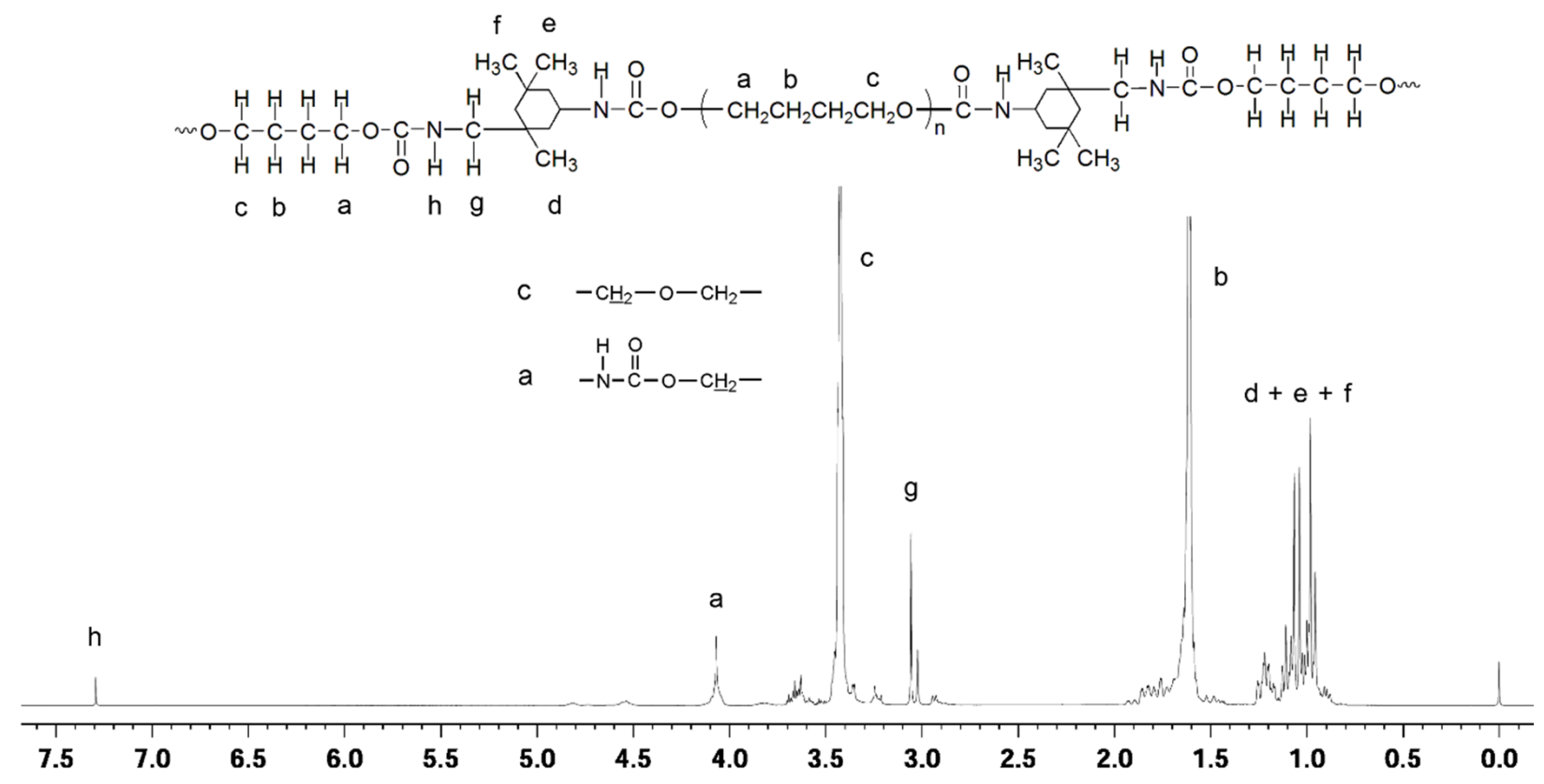

Figure 2. ${ }^{1} \mathrm{H}$ NMR spectrum of polyurethane (PUII).

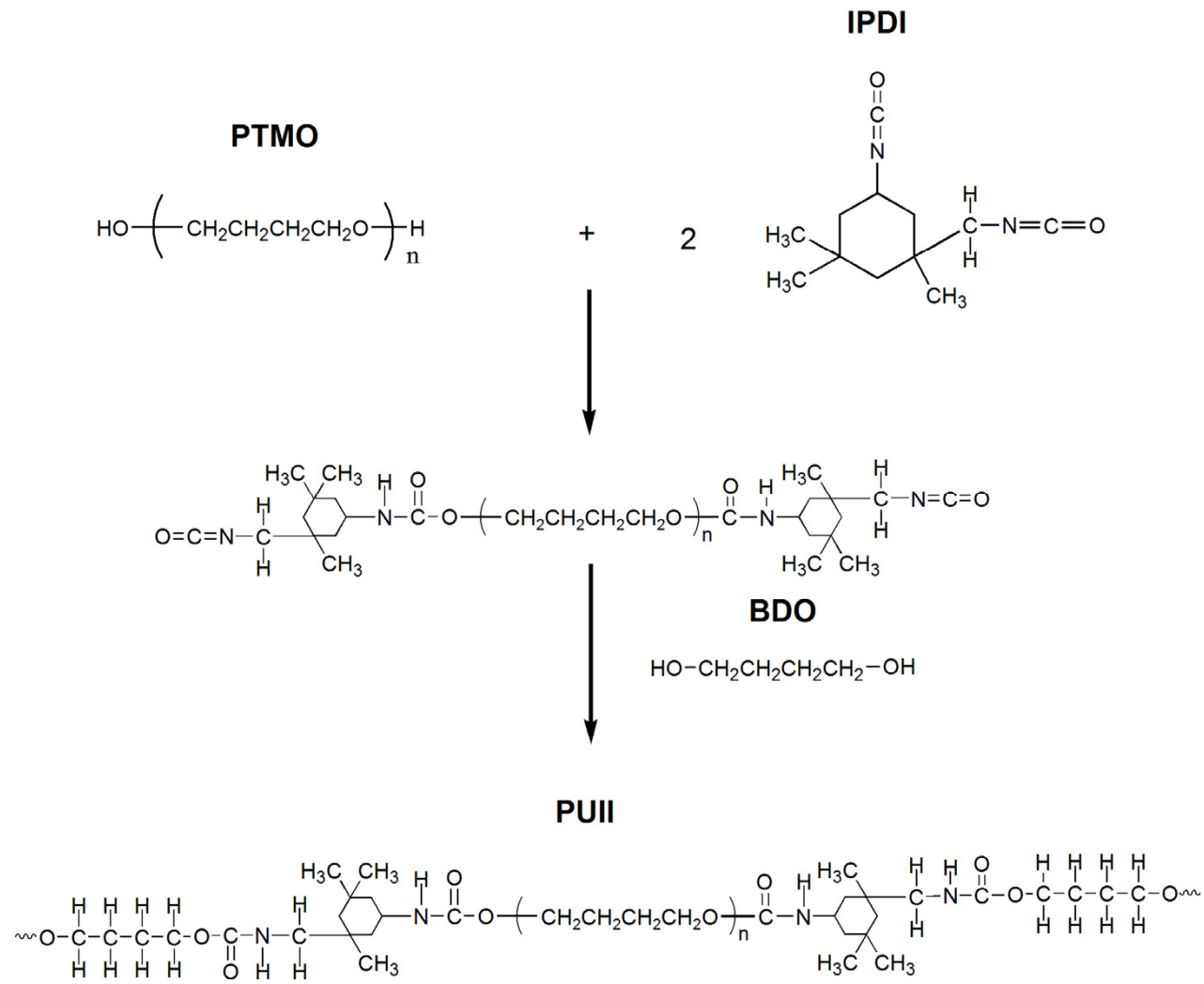

Scheme 1. Synthesis route of polyurethane (PUII).

\subsection{Preparation of PUII with Antibacterial Agent}

PUII with antibacterial agent was prepared by a one-step addition. Different amounts $(0.2 \%, 0.4 \%, 0.6 \%, 0.8 \%, 1.0 \%)$ of 1,3,5-Tris(2-hydroxyethyl) -hexahydro-1,3,5-triazine (TNO) was added as antibacterial agent to the PUII and allowed to stir for $60 \mathrm{~min}$. A solvent-casting method was used to prepare films of PUII with antibacterial agent. Specifically, about $10 \mathrm{~mL}$ dispersion was poured into a Teflon mold and dried at room temperature for one week. Finally, the films were dried at $45^{\circ} \mathrm{C}$ for one day and then sealed for storage. IR (Figure $1 \mathrm{~b}$ ): 
$3328 \mathrm{~cm}^{-1}(-\mathrm{NH}), 2939 \mathrm{~cm}^{-1}(-\mathrm{CH}), 1707 \mathrm{~cm}^{-1}$ (C=O), 1650 (C-N-C, TNO), $1546 \mathrm{~cm}^{-1}$ (-CN), $1239 \mathrm{~cm}^{-1}$ (C-O-C, PUII with antibacterial agent), $1108 \mathrm{~cm}^{-1}$ (C-O-C, PTMG).

\subsection{Characterization}

IR spectra were recorded with a Bruker-Vector 22 FTIR spectrophotometer (Billerica, $\mathrm{MA}, \mathrm{USA})$ using $\mathrm{KBr}$ disks. Nuclear magnetic resonance ( ${ }^{1} \mathrm{H}$ NMR) spectra were recorded in $\mathrm{CDCl}_{3}$ on a Bruker AVANCE III $400 \mathrm{MHz}$ apparatus. The molecular weights and their distributions of the polymers were determined by gel permeation chromatography (GPC) utilizing a Waters model 515 pump and a model 2410 differential refractometer with three styragel columns HT2, HT3 and HT4 connected in a serial fashion. THF was used as the eluent at a flow rate of $1.0 \mathrm{~mL} / \mathrm{min}$. Polystyrene standards with dispersity of 1.08-1.12 obtained from Waters were employed to calibrate the instrument. Scanning electron microscopy (SEM) measurements were carried out using a JEOL JSM-5600 LV SEM (Tokyo, Japan). The samples were fabricated by dropping one blob of the mixed solution of PUII, THF and water onto a glass patch, and then evaporated for $48 \mathrm{~h}$ under ambient temperature. Finally, the samples were coated with gold and observed by SEM. The DSC studies of the samples were carried out using a DSC8000 (TA instrument, New Castle, DE, USA). The samples were dried in a vacuum oven at $50^{\circ} \mathrm{C}$ for $28 \mathrm{~h}$ before use. The samples weighing between 5 and $15 \mathrm{mg}$ were sealed in a DSC pan and quenched to $-70^{\circ} \mathrm{C}$. The samples were then left to equilibrate for $15 \mathrm{~min}$ and heated to $200^{\circ} \mathrm{C}$ at a rate of $5{ }^{\circ} \mathrm{C} / \mathrm{min}$. The mechanical properties of the samples were measured on a universal testing machine (GT-TS-2000, Taipei, Taiwan) according to GB/T 1040-2006 with a tensile speed of $200 \mathrm{~mm} / \mathrm{min}$ at $23 \pm 2{ }^{\circ} \mathrm{C}$ to obtain the tensile strength and the breaking elongation [39]. The samples were casted from DMF solutions and shaped to strip products. The thickness and width of the specimens were 3.0 and $10 \mathrm{~mm}$, respectively. The length of the sample between the two pneumatic grips of Testing Machine was $50 \mathrm{~mm}$. Five measurements were conducted for each sample, and the results were averaged to obtain a mean value.

\subsection{Barrier Properties Experiment}

The transmittance/haze of the samples was measured on a transmittance/haze meter (WGT-S, Suzhou, China) according to GB2410-80 at $23 \pm 2{ }^{\circ} \mathrm{C}$ to obtain the transmittance value and the haze values. The samples were shaped to square products. The length and width of the specimens were $50 \mathrm{~mm}$. Three measurements were conducted for each sample, and the results were averaged to obtain a mean value. The oxygen permeability of the samples [39] was measured on a permeability tester (GDP-C, Berlin, Germany) according to GB/T1038-2000 at $23{ }^{\circ} \mathrm{C}$ to obtain the oxygen permeability coefficient. The samples were shaped to square products. The length and width of the specimens were $120 \mathrm{~mm}$. Four measurements were conducted for each sample, and the results were averaged to obtain a mean value. The water vapor permeability of the samples was measured on a Breathable Cup $\left(0.003 \mathrm{~m}^{2}\right.$, Chengde, China) according to GB/T1037-88 at $23 \pm 2{ }^{\circ} \mathrm{C}$ to obtain the permeability coefficient. The samples were shaped to $38 \mathrm{~mm}$ radius circular products. Three measurements were conducted for each sample, and the results were averaged to obtain a mean value.

\section{Results and Discussion}

\subsection{Synthesis of PUII}

Novel physically crosslinked polyurethane (PUII) based on isophorone diisocyanates was prepared by a conventional two-step method. PUII was prepared according to the procedure shown in Scheme 1. The chemical structure of the final polymer (PUII) was characterized with FTIR in KBr matrices. The FTIR spectra of PUII are shown in Figure 1, which demonstrate the presence of the expected functional groups. As shown in Figure 1, peaks at $3328 \mathrm{~cm}^{-1}(-\mathrm{NH}), 2939 \mathrm{~cm}^{-1}(-\mathrm{CH}), 1707 \mathrm{~cm}^{-1}(\mathrm{C}=\mathrm{O}), 1546 \mathrm{~cm}^{-1}(-\mathrm{CN}), 1239 \mathrm{~cm}^{-1}$ (C-O-C, PUII) and $1108 \mathrm{~cm}^{-1}$ (C-O-C, PTMG) are observed, which demonstrates that the synthesis is successful. 
${ }^{1} \mathrm{H}$ NMR spectrum of the PUII is shown in Figure 2. In the ${ }^{1} \mathrm{H}$ NMR spectrum of PUII (Figure 2), a peak corresponding to the $\mathrm{OCH}_{2}$ (a) of the PTMG, was observed at 4.06-4.07 ppm. A peak related to the $\mathrm{CH}_{2}$ (b) of PTMG appeared between 1.62 and $1.63 \mathrm{ppm}$. Other peaks are listed as follows: 3.40-3.41 ppm (c, $\left.\mathrm{CH}_{2} \mathrm{O}, \mathrm{PTMG}\right), 0.96-0.98 \mathrm{ppm}(\mathrm{d}, \mathrm{e}$, $\mathrm{f}, \mathrm{CH}_{3}$, IPDI), $3.06 \mathrm{ppm}$ (g, $\mathrm{CH}_{2}$, IPDI) and $7.29 \mathrm{ppm}$ (h, NH, PUII). This confirms the successful incorporation of IPDI to the polyurethane backbone.

GPC results indicate that the materials do not contain oligomers, and the PUII has molecular weight distributions (weight-average molecular weight of 72,000-79,000 and polydispersity of 1-2).

\subsection{Self-Assembly Behavior of PUII}

The self-assembly behavior of PUII was investigated by dissolving it in a mixed solution of THF and water. Six samples (THF:water = 90:10/80:20/70:30/60:40/50:50/40:60, $v / v$, corresponding serial number: 1-6) were prepared for SEM measurement. As shown in Figure 3, the samples became more pellucid due to the quantity of water decreasing. The samples were fabricated by dropping one blob of the mixed solution of PUII, THF and water onto a glass patch, and then evaporated for $48 \mathrm{~h}$ under ambient temperature. Finally, the samples were coated with gold and observed by SEM.

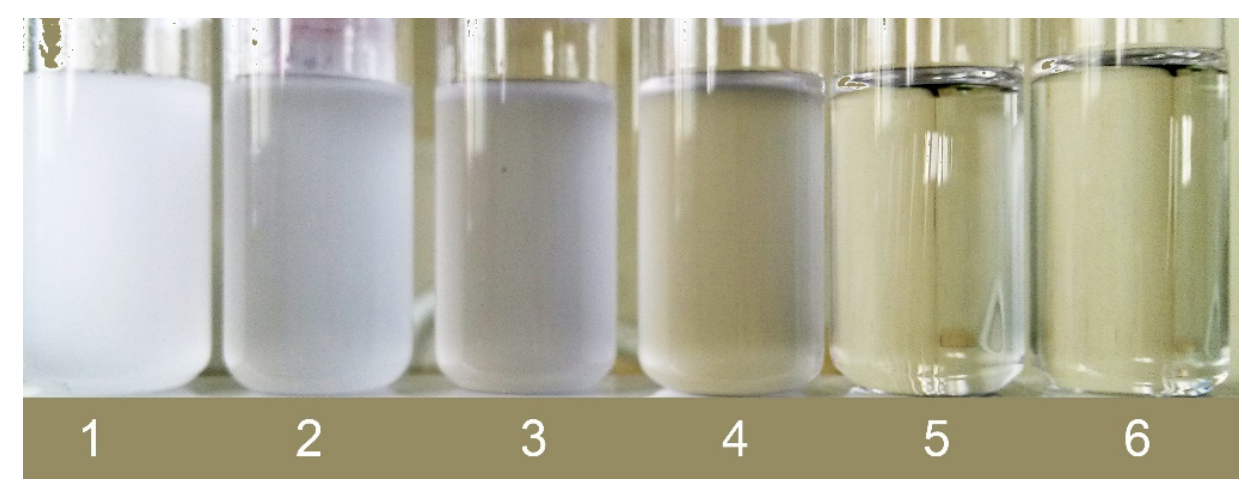

Figure 3. Samples of PUII self-assembly behavior (THF:water $=$ 90:10/80:20/70:30/60:40/50:50/40:60, $v / v$, corresponding serial number: 1-6).

As shown in Figure 4a-d, the SEM images of samples demonstrate that the polymer creates irregular globular morphologies. The average particle diameter was calculated by SEM images and the sizes range from $1 \mu \mathrm{m}$ to $7 \mu \mathrm{m}$. The samples of number 6 and 1 (THF:water $=40: 60 / 90: 10$ ) are correspondingly shown in Figure 4a,c. Figure 4b,d, respectively, reveal particulars of number 6 and 1. The space between irregular globular morphologies is gradually diminished when the quantity of water increases. So, water quantity plays an important role in the self-assembly behavior. In this study, number 5 (THF:water $=50: 50$ ) is a critical value. When the ratio of THF/water moves over this point, the aggregation becomes uncontrollable. We have created micron materials with good reproducibility by a solvent-induced assembly process, as confirmed by microscopic techniques of SEM. This is the first time that such a variety of morphologies of PU without dissolvents based on isophorone diisocyanates is found in the literature. 

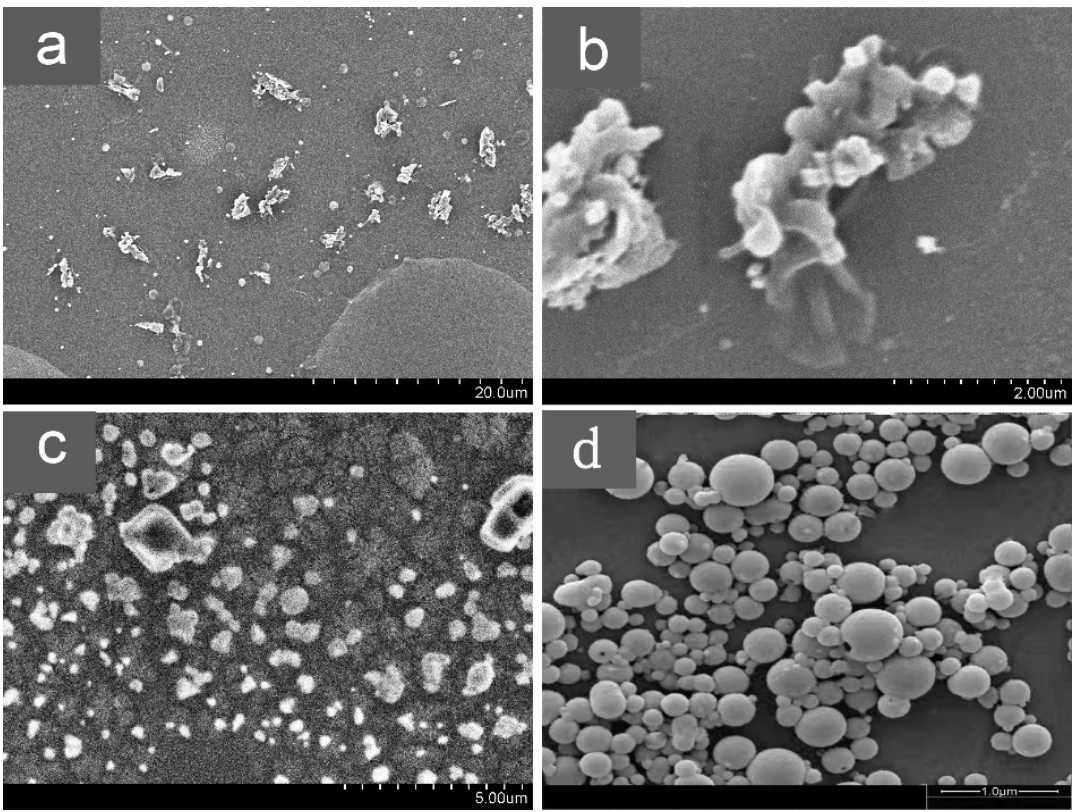

Figure 4. SEM images of PUII self-assembly behavior (The samples of number 6 and 1 (THF:water = 40:60/90:10) are correspondingly shown in (a,c). (b,d), respectively, reveal particulars of number 6 and 1).

\subsection{Barrier Properties of PUII}

Different amounts of antimicrobial agents result in different outcomes. The antimicrobial PUII films with different amounts $(0.2 \%, 0.4 \%, 0.6 \%, 0.8 \%, 1.0 \%)$ of $1,3,5$-Tris $(2$ hydroxye-thyl)hexahydro-1,3,5-triazine (TNO) were measured for the haze and transmittance. The results are presented in Table 1. With an increase in the amounts of antimicrobial agents, transmittance of the films reduced and the haze of the films increased. The transparency of the antibacterial PUII films was lower than that of the PUII films.

Table 1. The transmittance and haze of the PUII films.

\begin{tabular}{ccc}
\hline $\begin{array}{c}\text { The Content of Antibacterial Agent } \\
(\mathbf{\%})\end{array}$ & $\begin{array}{c}\text { Transmittance } \\
\mathbf{( \% )}\end{array}$ & $\begin{array}{c}\text { Haze } \\
\mathbf{( \% )}\end{array}$ \\
\hline 0 & 89.7 & 51.11 \\
0.2 & 73.5 & 90.23 \\
0.4 & 70.2 & 90.31 \\
0.6 & 66.3 & 91.22 \\
0.8 & 62.8 & 92.13 \\
1.0 & 61.1 & 92.91 \\
\hline
\end{tabular}

Oxygen permeability testing results of the antibacterial PUII films presented in Figure 5. Oxygen permeability coefficients of the antibacterial polyurethane films was higher, and it decreased with an increase in the amounts of antimicrobial agents. The reason is that the antimicrobial agents mixed into the polyurethane physically. The antimicrobial agents attached to the surface of the film and formed a protective film. The variation of oxygen permeability stabilized slightly when the amount of antimicrobial agents arrived $1 \%$ gradually. The water vapor permeability testing results of the PUII films with different amounts of antimicrobial agents are shown in Figure 6. The water vapor permeability coefficient of the antibacterial PUII films decreased first, and it increased with an increase in the amount of antimicrobial agents $(0.8 \%, 1.0 \%)$. The reason is that antimicrobial agents mixed into the polyurethane physically. The antimicrobial agents attached to the surface of the film and formed a protective film. 


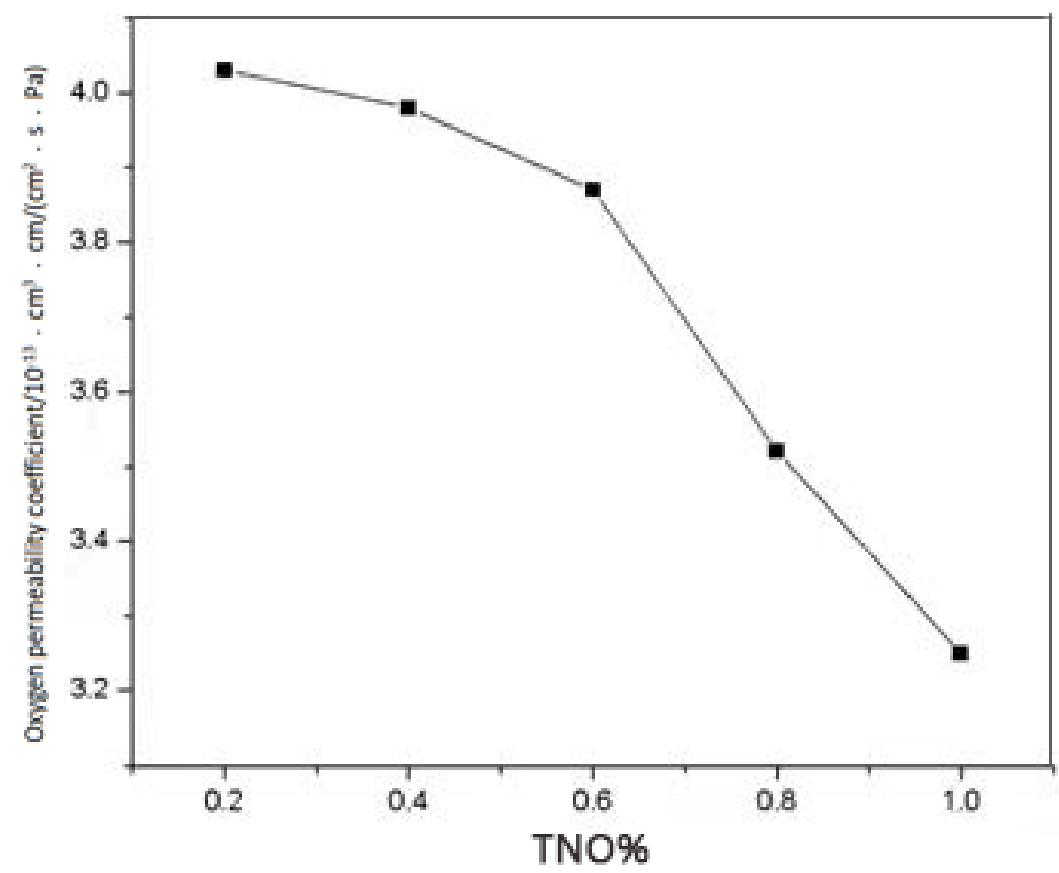

Figure 5. The oxygen permeability coefficient of the antibacterial PUII films.

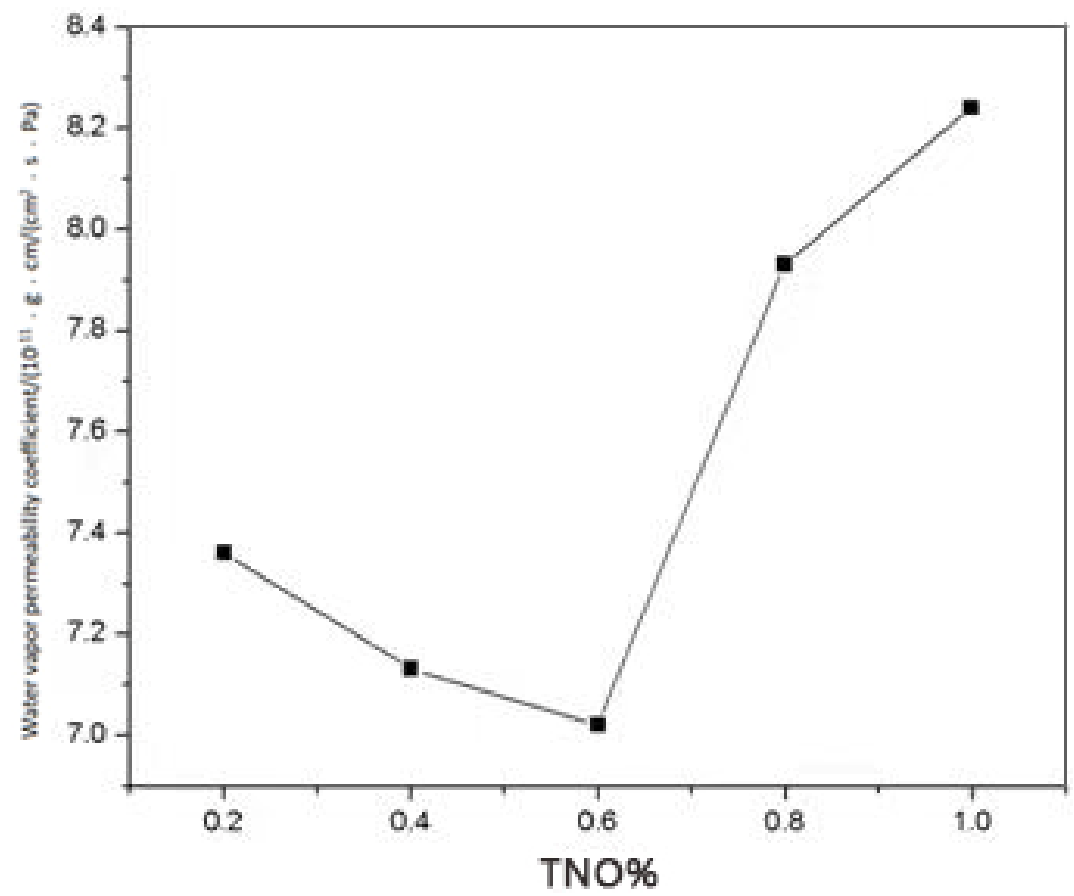

Figure 6. The water vapor permeability coefficient of the antibacterial PUII films.

\subsection{Mechanical Properties and Thermal Analysis of PUII}

The mechanical properties of the PUII films and the antimicrobial PUII films were measured on a universal testing machine (GT-TS-2000, Taiwan) according to GB/T 1040-2006 with a tensile speed of $200 \mathrm{~mm} / \mathrm{min}$ at $23 \pm 2{ }^{\circ} \mathrm{C}$ to obtain the tensile strength and the breaking elongation. The tensile strength and the breaking elongation of the PUII films and the anti-microbial PUII films with different amounts $(0.2 \%, 0.4 \%, 0.6 \%, 0.8 \%, 1.0 \%)$ of 1,3,5-Tris(2-hydroxyethyl)hexahydro-1,3,5-triazine (TNO) are shown in Table 2. The tensile strength of the PUII films increased as the amounts of the antibacterial agent increased. The tensile strength of conventional PE films is about $20-40 \mathrm{MPa}$, and the breaking elongation of conventional PE films is about $300-500 \%$. The tensile strength and the breaking elongation 
of the PUII films and the antimicrobial PUII films are higher than that of the PE film, which suggests that the PUII films and the antimicrobial PUII films showed better mechanical properties in comparison with PE films. The PUII films and the antimicrobial PUII films possess higher tensile strength and breaking elongation compared to PVC films. Thermal analyses of the PUII films and antimicrobial PUII films were measured by DSC. The DSC studies of the PUII films and antimicrobial PUII films were carried out using a DSC8000 (TA instrument, New Castle, DE, USA). The PUII films and the antimicrobial PUII films were dried in a vacuum oven at $50{ }^{\circ} \mathrm{C}$ for $28 \mathrm{~h}$ before use. The DSC studies show that the antimicrobial PUII films exhibit good thermal properties. The antimicrobial PUII films show two Tgs; the lower temperature shows the soft segment $\operatorname{Tg}\left(-20.9^{\circ} \mathrm{C}\right)$ and the higher temperature shows the hard segment $\operatorname{Tg}\left(10{ }^{\circ} \mathrm{C}\right)$.

Table 2. Mechanical performance of the PUII films.

\begin{tabular}{ccc}
\hline The Content of Antibacterial Agent (\%) & Breaking Elongation (\%) & Tensile Strength (MPa) \\
\hline 0 ave. ${ }^{\text {a }}$ & $502.7 \pm 40.1$ & $41.1 \pm 3.2$ \\
0.2 ave. & $519.9 \pm 43.2$ & $42.3 \pm 3.5$ \\
0.4 ave. & $528.8 \pm 47.5$ & $43.5 \pm 4.2$ \\
0.6 ave. & $539.6 \pm 45.3$ & $44.2 \pm 3.8$ \\
0.8 ave. & $557.8 \pm 48.6$ & $45.1 \pm 5.2$ \\
1.0 ave. & $581.9 \pm 52.8$ & $46.9 \pm 4.7$ \\
\hline
\end{tabular}

a The average number of 5 films. Data are expressed as mean \pm SD.

\subsection{Antimicrobial Properties}

The inhibition zone method was employed. The PUII films with different amounts $(0.2 \%, 0.4 \%, 0.6 \%, 0.8 \%, 1.0 \%)$ of 1,3,5-Tris(2-hydroxyethyl)hexahydro-1,3,5-triazine (TNO) were challenged with Escherichia coli, Staphylococcus aureus, Bacillus subtilis and Gray mold, as shown in Table 3 and Figures 7-10. The results show that when a small amount of antibacterial agent was added, the antibacterial effect of films on Botrytis cinerea was more obvious. When more antibacterial agent was added, the films showed a better inhibitory effect on Staphylococcus aureus and Escherichia coli. In addition, the inhibitory effect on the Bacillus subtilis was not effective.
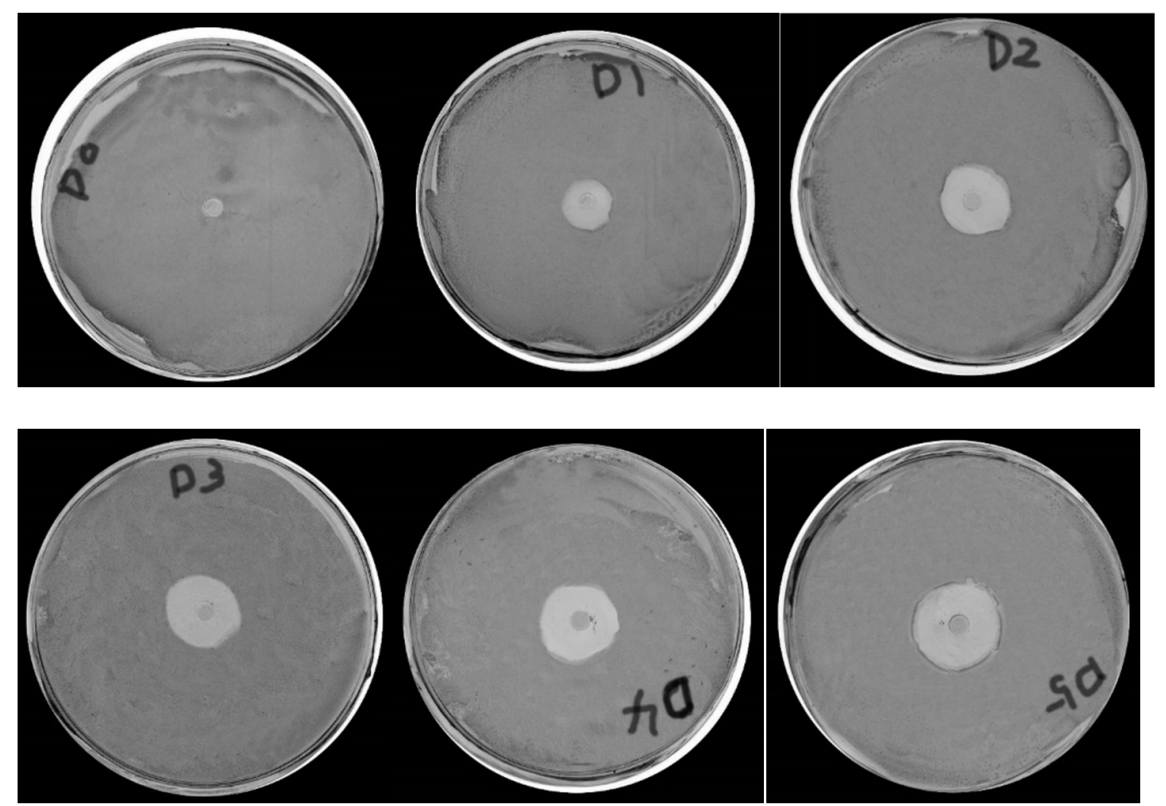

Figure 7. The inhibiting capacity of films with different amounts $(0 \%, 0.2 \%, 0.4 \%, 0.6 \%, 0.8 \%, 1.0 \%)$ of 1,3,5-Tris(2-hydroxyethyl)hexahydro-1,3,5-triazine (TNO) on Escherichia coli $\left(\mathrm{D}_{0}: \mathrm{TNO} \%=0 \%\right.$; $\left.\mathrm{D}_{1}: \mathrm{TNO} \%=0.2 \% ; \mathrm{D}_{2}: \mathrm{TNO} \%=0.4 \% ; \mathrm{D}_{3}: \mathrm{TNO} \%=0.6 \% ; \mathrm{D}_{4}: \mathrm{TNO} \%=0.8 \% ; \mathrm{D}_{5}: \mathrm{TNO} \%=1.0 \%\right)$. 

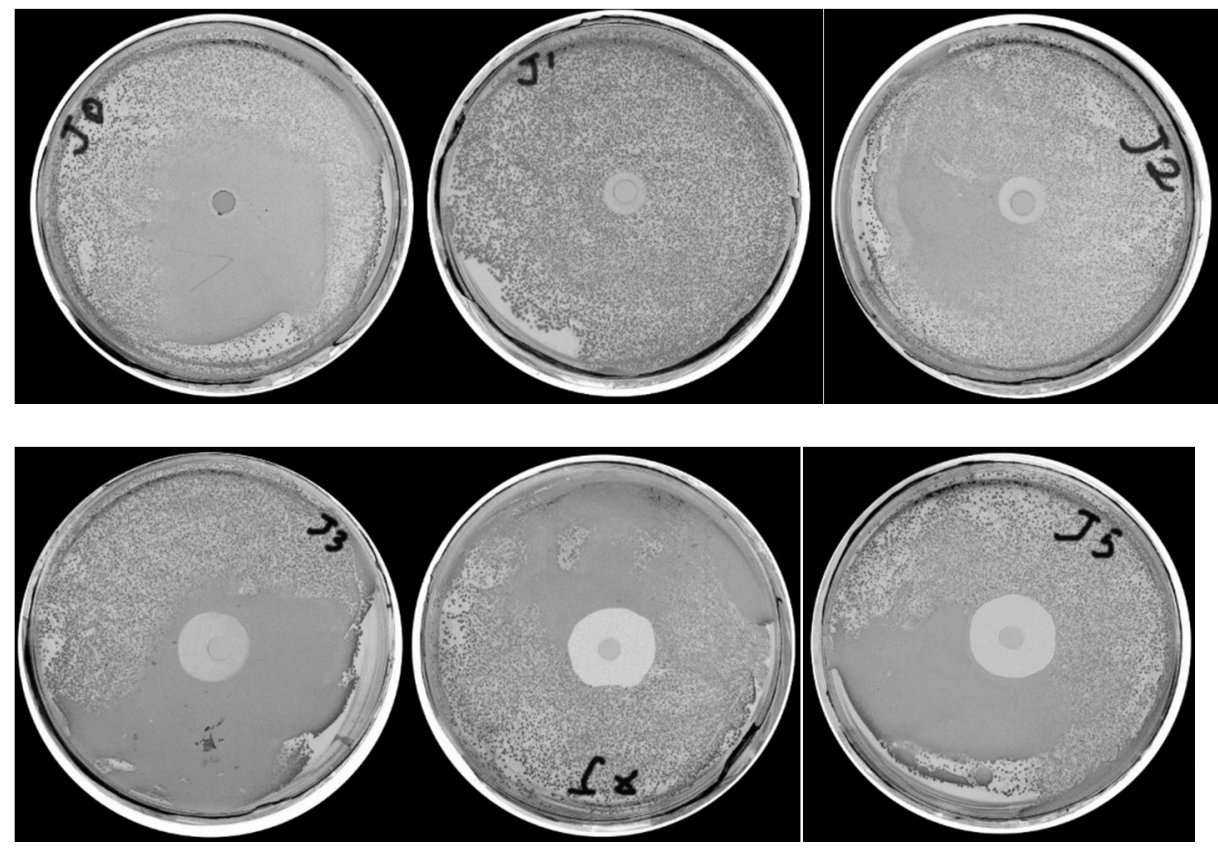

Figure 8. The inhibiting capacity of films with different amounts $(0 \%, 0.2 \%, 0.4 \%, 0.6 \%, 0.8 \%, 1.0 \%)$ of 1,3,5-Tris(2-hydroxyethyl)hexahydro-1,3,5-triazine (TNO) on Staphylococcus aureus $\left(\mathrm{J}_{0}: \mathrm{TNO} \%=0 \%\right.$; $\left.\mathrm{J}_{1}: \mathrm{TNO} \%=0.2 \% ; \mathrm{J}_{2}: \mathrm{TNO} \%=0.4 \% ; \mathrm{J}_{3}: \mathrm{TNO} \%=0.6 \% ; \mathrm{J}_{4}: \mathrm{TNO} \%=0.8 \% ; \mathrm{J}_{5}: \mathrm{TNO}^{2}=1.0 \%\right)$.
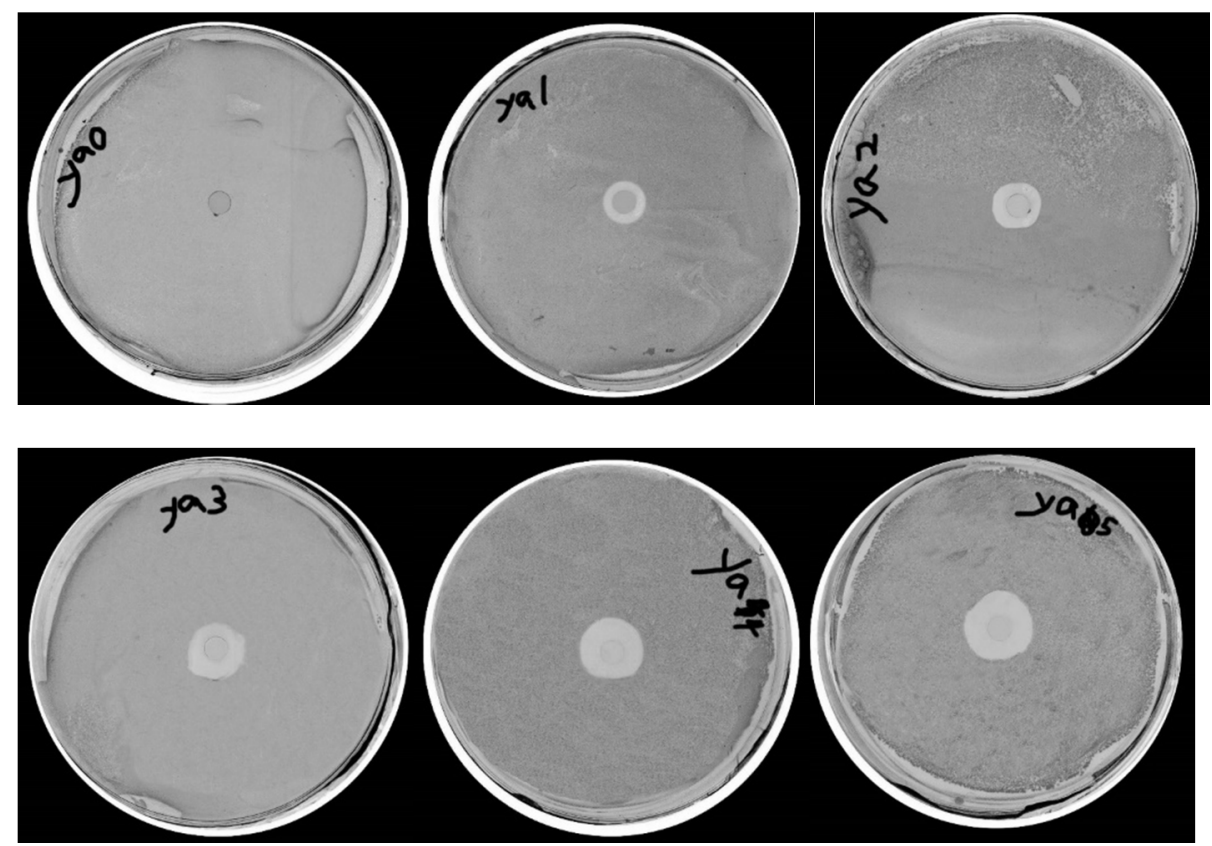

Figure 9. The inhibiting capacity of films with different amounts $(0 \%, 0.2 \%, 0.4 \%, 0.6 \%, 0.8 \%, 1.0 \%)$ of 1,3,5-Tris(2-hydroxyethyl)hexahydro-1,3,5-triazine (TNO) on Bacillus subtilis ( $\mathrm{ya}_{0}: \mathrm{TNO} \%=0 \%$; $\mathrm{ya}_{1}: \mathrm{TNO} \%=0.2 \% ; \mathrm{ya}_{2}: \mathrm{TNO} \%=0.4 \% ; \mathrm{ya}_{3}: \mathrm{TNO} \%=0.6 \% ; \mathrm{ya}_{4}: \mathrm{TNO} \%=0.8 \% ; \mathrm{ya}_{5} \mathrm{TNO} \%=1.0 \%$ ). 

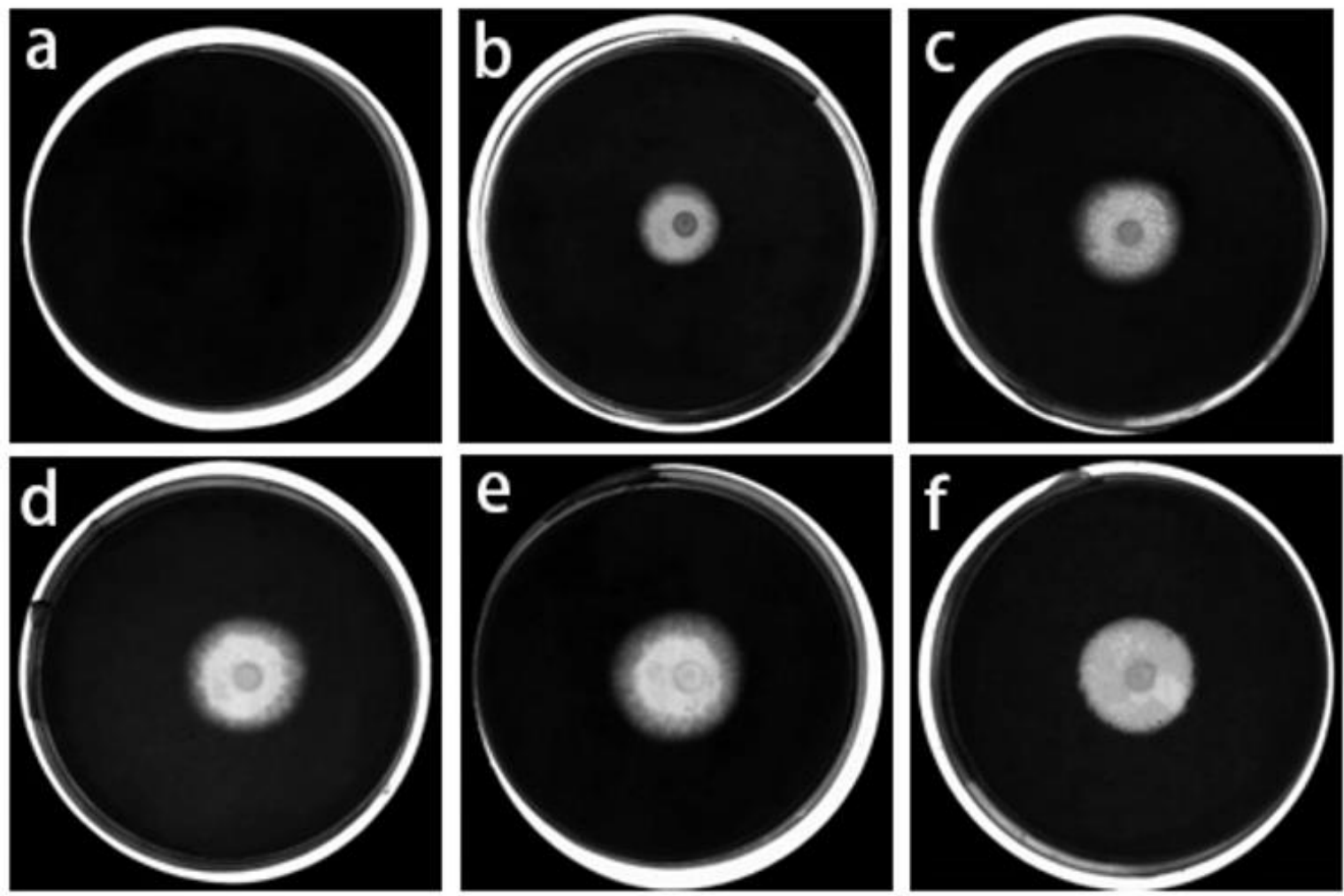

Figure 10. The inhibiting capacity of films with different amounts $(0 \%, 0.2 \%, 0.4 \%, 0.6 \%, 0.8 \%$, $1.0 \%$ ) of 1,3,5-Tris(2-hydroxyethyl)hexahydro-1,3,5-triazine (TNO) on Gray mold ((a): TNO $\%=0 \%$; (b): $\mathrm{TNO} \%=0.2 \%$; (c): $\mathrm{TNO} \%=0.4 \%$; (d): $\mathrm{TNO} \%=0.6 \%$; (e): $\mathrm{TNO} \%=0.8 \%$; (f): $\mathrm{TNO} \%=1.0 \%$ ).

Table 3. The antibacterial circle diameter of different samples.

\begin{tabular}{ccccc}
\hline The Content of & \multicolumn{4}{c}{ The Antibacterial Circle Diameter/mm } \\
\cline { 2 - 5 } Antibacterial Agent/\% & Escherichia coli & Staphylococcus aureus & Bacillus subtilis & Gray mold \\
\hline 0 & 0 & 0 & 0 & 0 \\
0.2 & 14.1 & 10.2 & 10.3 & 17.8 \\
0.4 & 18.1 & 11.7 & 13.9 & 18.5 \\
0.6 & 19.3 & 18.3 & 15.5 & 19.1 \\
0.8 & 20.9 & 21.9 & 17.1 & 22.9 \\
1.0 & 23.2 & 22.1 & & 2 \\
\hline
\end{tabular}

\section{Conclusions}

Novel physically crosslinked polyurethane (PUII) based on isophorone diisocyanates was prepared by a conventional two-step method. The chemical structures of the PUII were characterized by FTIR, ${ }^{1} \mathrm{H}$ NMR, GPC, SEM and DSC. The self-assembly behavior of PUII has also been tested, and the results showed that the micron materials created irregular globular morphologies. This investigation provides a clear insight into the solvent-induced self-assembly in the novel PUII polymer hydrogels for the various morphologies and sizes ranging from micron- to nanometer-sized pores and spheres. The antimicrobial property of the PUII films containing an antibacterial agent was examined against Escherichia coli, Staphylococcus aureus, Bacillus subtilis and Gray mold and showed good antibacterial properties. The mechanical evaluation shows that polyurethane (PUII) materials exhibit good mechanical properties. The new PUII has good mechanical properties, good antibacterial properties, and poor barrier properties compared with other polyurethanes. 


\begin{abstract}
Author Contributions: J.D.: data curation, formal analysis, investigation, visualization, writingoriginal draft, writing - review and editing. G.J.: conceptualization, formal analysis, funding acquisition, methodology, project administration, writing - review and editing. All authors have read and agreed to the published version of the manuscript.
\end{abstract}

Funding: This work was supported by the China Postdoctoral Science Foundation (No. 200902090) and Tianjin Enterprise Science and Technology Commissioner Project (No. 21YDTPJC00570).

Institutional Review Board Statement: Not applicable.

Informed Consent Statement: Not applicable.

Data Availability Statement: The authors declare data availability.

Acknowledgments: This work was supported by the China Postdoctoral Science Foundation (No. 200902090) and Tianjin Enterprise Science and Technology Commissioner Project (No. 21YDTPJC00570).

Conflicts of Interest: The authors declare no conflict of interest.

\title{
References
}

1. Xia, Y.; Zhang, Z.Y.; Kessler, M.R.; Stecher, B.B.; Larock, R.C. Antibacterial soybean-Oil-based cationic polyurethane coatings prepared from different amino polyols. ChemSusChem 2012, 5, 2221-2227. [CrossRef]

2. Akindoyo, J.O.; Beg, M.D.H.; Ghazali, S.; Islam, M.R.; Jeyaratnam, N.; Yuvaraj, A.R. Polyurethane types, synthesis and applications. RSC Adv. 2016, 6, 114453-114482. [CrossRef]

3. Engels, H.W.; Pirkl, H.G.; Albers, R.; Albach, R.W.; Krause, J.; Hoffmann, A.; Casselmann, H.; Dormish, J. Polyurethanes: Versatile materials and sustainable problem solvers for today's challenges. Angew. Chem. Int. Ed. 2013, 52, 9422-9441. [CrossRef]

4. Zhang, Z.P.; Rong, M.Z.; Zhang, M.Q. Polymer engineering based on reversible covalent chemistry: A promising innovative pathway towards new materials and new functionalities. Prog. Polym. Sci. 2018, 80, 39-93. [CrossRef]

5. Scheutz, G.M.; Lessard, J.J.; Sims, M.B.; Sumerlin, B.S. Adaptable crosslinks in polymeric materials: Resolving the intersection of thermoplastics and thermosets. J. Am. Chem. Soc. 2019, 141, 16181-16196. [CrossRef]

6. Zee, N.J.V.; Nicolaÿ, R. Vitrimers: Permanently cross-linked polymers with dynamic network topology. Prog. Polym. Sci. 2020, 7 , 30-38.

7. Nevejans, S.; Ballard, N.; Fernández, M.; Reck, B.; Asua, J.M. Flexible aromatic disulfide monomers for high-performance self-healable linear and cross-linked poly(urethane-urea) coatings. Polymer 2019, 166, 229-238. [CrossRef]

8. Zhang, J.; Shen, H.Z.; Zhang, X.; Li, H.Y. Experimental and theoretical investigation of mechanical behavior related to temperature, humidity and strain rate on silane-modified polyurethane sealant. Polym. Test. 2021, 103, 107370. [CrossRef]

9. Behera, P.K.; Mondal, P.; Singha, N.K. Self-healable and ultrahydrophobic polyurethane-poss hybrids by diels-alder "click" reaction: A new class of coating material. Macromolecules 2018, 51, 4770-4781. [CrossRef]

10. Gao, Z.; Peng, J.; Zhong, T.; Sun, J.; Wang, X.; Yue, C. Biocompatible elastomer of waterborne polyurethane based on castor oil and polyethylene glycol with cellulose nanocrystals. Carbohydr. Polym. 2012, 87, 2068-2075. [CrossRef]

11. Chen, J.; Hu, D.; Li, Y.; Zhu, J.; Du, A.; Zeng, J. Castor oil-based high performance and reprocessable poly(urethane urea) network. Polym. Test. 2018, 70, 174-179. [CrossRef]

12. Rangamani, A.; Alabi, C.A. Effect of backbone and end-group regioisomerism on thermomechanical properties of vanillin-based polyurethane networks. Polym. Chem. 2021, 12, 1526-1532. [CrossRef]

13. Liu, W.; Fang, C.; Wang, S.; Huang, J.; Qiu, X. High-performance lignin-containing polyurethane elastomers with dynamic covalent polymer networks. Macromolecules 2019, 52, 6474-6480. [CrossRef]

14. Ma, X.; Chen, J.; Zhu, J.; Yan, N. Lignin-based polyurethane: Recent advances and future perspectives. Macromol. Rapid Commun. 2021, 42, 2000492. [CrossRef] [PubMed]

15. Lee, S.-H.; Shin, S.-R.; Lee, D.-S. Self-healing of cross-linked PU via dual-dynamic covalent bonds of a Schiff base from cystine and vanillin. Mater. Des. 2019, 172, 107774. [CrossRef]

16. Zheng, N.; Fang, Z.; Zou, W.; Zhao, Q.; Xie, T. Thermoset shape-memory polyurethane with intrinsic plasticity enabled by transcarbamoylation. Angew. Chem. Int. Ed. 2016, 55, 11421-11425. [CrossRef]

17. Li, C.Y.; Chen, J.H.; Chien, P.C.; Chiu, W.Y.; Chen, R.S.; Don, T.M. Preparation of poly (IPDI-PTMO-siloxanes) and influence of siloxane structure on reactivity and mechanical properties. Polym. Eng. Sci. 2007, 47, 625-632. [CrossRef]

18. Mishra, A.; Singh, S.K.; Dash, D.; Aswal, V.K.; Maiti, B.; Misra, M.; Maiti, P. Self-assembled aliphatic chain extended polyurethane nanobiohybrids: Emerging hemocompatible biomaterials for sustained drug delivery. Acta Biomater. 2014, 10, 2133-2146. [CrossRef]

19. Andreas, L.; Robert, L. Biodegradable, elastic shape-memory polymers for potential biomedical applications. Science 2002, 296, 1673-1676.

20. Madbouly, S.A.; Otaigbe, J.U. Recent advances in synthesis, characterization and rheological properties of polyurethanes and POSS/polyurethane nanocomposites dispersions and films. Prog. Polym. Sci. 2009, 34, 1283-1332. [CrossRef]

21. Zhang, Y.; Wang, L.; Zhang, Z.; Zhang, Y.; Tuo, X. Synthesis and simultaneous self-assembly of multiblock fluorinated polyurethane in iniferter polymerization. J. Polym. Sci. Part A Polym. Chem. 2013, 51, 2161-2170. [CrossRef] 
22. Rogulska, M.; Kultys, A.; Podkoscielny, W. Studies on thermoplastic polyurethanes based on new diphenylethane-derivative diols. II. Synthesis and characterization of segmented polyurethanes from HDI and MDI. Eur. Polym. J. 2007, 43, 1402-1414. [CrossRef]

23. Singh, R.P.; Tomer, N.S.; Bhadraiah, S.V. Photo-oxidation studies on polyurethane coating: Effect of additives on yellowing of polyurethane. Polym. Degrad. Stab. 2001, 73, 443-446. [CrossRef]

24. Thapliyal, B.P.; Chandra, R. Advances in photodegradation and stabilization of polyurethanes. Prog. Polym. Sci. 1990, 15, 735-750. [CrossRef]

25. Desai, S.D.; Emanuel, A.L.; Sinha, V.K. Polyester polyol based polyurethane adhesive: Effect of treatment on rubber surface. J Polym. Res. 2003, 10, 141-149. [CrossRef]

26. Chen, C.J. Waterborne polyurethane adhesive and its application in dry compound. Plastics Packag. 2007, 17, 50-54.

27. Zhukova, E.E.; Shtilman, M.I.; Iordanskii, A.L. Polyurethane films with antimicrobial properties, intended for the development of coatings preventing catheter-associated bloodstream infections. Int. Polym. Sci. Technol. 2013, 40, 51-55. [CrossRef]

28. Mohammadi, A.; Doctorsafaei, A.H.; Burujeny, S.B.; Rudbari, H.A.; Kordestani, N.; Najafabadi, S.A.A. Silver(I) complex with a Schiff base ligand extended waterborne polyurethane: A developed strategy to obtain a highly stable antibacterial dispersion impregnated with in situ formed silver nanoparticles. Chem. Eng. J. 2021, 381, 122776. [CrossRef]

29. Liu, K.; Su, Z.G.; Miao, S.D.; Ma, G.H.; Zhang, S.P. UV-curable enzymatic antibacterial waterborne polyurethane coating. Biochem. Eng. J. 2016, 113, 107-113. [CrossRef]

30. Muzaffar, S.; Bhatti, I.A.; Zuber, M.; Bhatti, H.N.; Shahid, M. Study of the UV protective and antibacterial properties of aqueous polyurethane dispersions extended with low molecular weight chitosan. Int. J. Biol. Macromol. 2017, 94, 51-60. [CrossRef] [PubMed]

31. Jiang, G.C.; Tuo, X.L.; Wang, D.R.; Li, Q. Synthesis and properties novel polyurethane-hexafluorobutyl methacrylate copolymers. J. Mater. Sci. Mater. Med. 2012, 23, 1867-1877. [CrossRef] [PubMed]

32. Marsat, J.N.; Heydenreich, M.; Kleinpeter, E.; Berlepsch, H.V.; BooTtcher, C.; Laschewsky, A. Self-Assembly into Multicompartment Micelles and Selective Solubilization by Hydrophilic- Lipophilic- Fluorophilic Block Copolymers. Macromolecules 2011, 44, 2092-2105. [CrossRef]

33. Jenekhe, S.A.; Chen, X.L. Self-assembly of ordered microporous materials from rod-coil block copolymers. Science 1999, 283, 372-375. [CrossRef]

34. Li, X.M.; He, J.D. Studies on Amphiphilic Triblock Copolymer PHB-PEG-PHB and Its Nanoparticles. Acta Polym. Sin. 2015, 1, $41-48$.

35. Winey, K.I.; Thomas, E.L.; Fetters, L.J. Ordered morphologies in binary blends of diblock copolymer and homopolymer and characterization of their intermaterial dividing surfaces. J. Chem. Phys. 1991, 95, 9367-9375. [CrossRef]

36. Li, Z.; Hillmyer, M.A.; Lodge, T.P. Morphologies of multicompartment micelles formed by ABC miktoarm star terpolymers. Langmuir 2006, 22, 9409-9417. [CrossRef]

37. Amundson, K.; Helfand, E.; Davis, D.D.; Quan, X.; Patel, S.S.; Smith, S.D. Effect of an electric field on block copolymer microstructure. Macromolecules 1991, 24, 6546-6548. [CrossRef]

38. Xu, T.; Goldbach, J.T.; Russell, T.P. Sequential, orthogonal fields: A path to long-range, 3-D order in block copolymer thin films. Macromolecules 2003, 36, 7296-7300. [CrossRef]

39. Wang, B.; Fan, Y.-L.; Jiang, G.-C.; Liu, J.-Y. Preparation and Characterization of New Antibacterial Polyurethane Packaging Film. Packag. Eng. 2021, 42, 155-161. 